\title{
PLA MATERIAL SURFACE PROPERTIES EVALUATION PREPARED BY ADDITIVE TECHNOLOGY
}

\author{
Zbynek STUDENY, Ondrej SEVERA, David DEMYDENKO, Tomas DRAZAN \\ University of Defence, Faculty of Military Technology, Brno, Czech Republic, EU, zbynek.studeny@unob.cz
}

https://doi.org/10.37904/metal.2021.4228

\begin{abstract}
The article deals with tribological evaluation of surface properties and their changes in biodegradable material PLA (polylactic acid). On samples prepared using 3D FFF printing technology, with uneven filling density, printed on the Prusa printer. The surface texture of the samples was evaluated in terms of microgeometry, which was created by the process of 3D printing. The TalySurf CLI1000 was used to evaluate the texture. The surface texture was measured with an inductive touch sensor. Subsequently, the samples surfaces were cyclically stressed with a defined load always on the same path. Cyclic surface loading was performed and measured by a UMT Bruker tribometer. During the cyclic reciprocating motion, the tribological properties of the surface, especially the coefficient of friction, were studied. The values of applied loads were constant. Traces obtained during tribological testing were documented on an Olympus DSX 100 optical microscope. Trace parameters were verified by profilometric analysis on a TalySurf CLI1000. The values obtained, in particular the track widths, can be used to determine the wear coefficient.
\end{abstract}

Keywords: PLA, 3D printing, coefficient of friction

\section{INTRODUCTION}

At present, additive technologies are increasingly used for the production of machine parts. These technologies allow the production of components with or without the use of conventional technologies, i.e. like a post processing. One of the intended additive technologies is the technology of component production using 3D printing. This technology has a wide application of the use of machine parts, e.g. in safety areas. This technology is very variable. Both in terms of materials and in terms of the final shape or dimensions of the finished parts - see [1-5]. In the environment of the defense industry or military technologies [6,7], these technologies find their significant application, as stated, for example, by the authors Kim, Ahn [8] within NATO armies, or Yang, et al. [9].

However, it is necessary to know the machine part made by 3D printing technology before using it. Know its limits, i.e. the limits beyond which it is no longer possible to go in terms of the safety of the whole structure. These boundaries can be both strength and structural. These can be the limits of the resistance of the material, its surface, temperature resistance, etc.

This article deals with selected parameters, which then together describe the resistance of the selected PLA material. The PLA material is a biodegradable material, it is polylactic acid. For the needs of the experiment, samples were printed at the workplace of the Department of Mechanical Engineering of the University of Defense. FFF technology was used to print the samples on a 3D printer from the Prusacompany. The PLA material was chosen for its possible applications in the defense and security industry or in military technology.

After printing the samples, the surface texture was evaluated. The evaluation was performed with respect to microgeometry, which is characteristic of surfaces created by the $3 \mathrm{D}$ printing process. Surface texture evaluation was performed with a TalySurf CLI1000. After documentation of the surface, cyclic loading with a Bruker UMT-3 tribometer performed tribological experiments. The Ball on Flat method performed testing. 
The tests of tribological properties make it possible to investigate changes in a number of quantities and parameters in the tribological system. The tribological system includes an indentor fitted with a ball or tip and an examined surface, i.e. a sample. The system also includes an environment with a defined temperature and humidity and, last but not least, a machine - a tribometer, which controls the entire system. From the point of view of objective comparison of measurement results, the implementation of tribological tests should be performed in laboratory conditions. From the point of view of evaluation of tribological properties, friction processes were studied.

In general, it can be stated for the coefficient of friction that its value is influenced by the condition of the sample surface, its roughness and the condition of the indenter surface. When overcoming the roughness, the load in the contact surface of the sample and the indenter changes. On the value of the coefficient of friction also affects the measuring time, temperature, distance that must be overcome indenter and other influences. For these reasons, it is appropriate to measure in laboratory conditions, where a number of parameters can be set, controlled, checked and the results of different measurements can then be compared with each other.

For the PLA material, a decrease in mechanical properties depending on increasing temperature is known and published [10]. This decrease in mechanical properties is probably associated with a local increase in temperature at the point of contact between the pin and the sample area. In order to obtain valid information on the dependence of temperature on the surface resistance of the sample, the temperature was measured in real time during the experiment. The FLIR T610 thermal camera was used to measure the temperature.

\section{MATERIAL AND SAMPLE PREPARATION}

The experimental material chosen for measuring the coefficient of friction was a 3D printed PLA polymer using FFF printing technology by a Prusa printer. It is a Czech 3D printer manufactured by Prusa Research. Among other things, this printer allows to set different levels of filling of internal structures [11, 12]. The samples were printed in the form of blocks $(30 \times 30) \mathrm{mm}$ and $6 \mathrm{~mm}$ thick. $70 \%$ of internal filling was used for the measured blocks, surface $100 \%$ of filling. We use $70 \%$ of the inner filling as a standard for mutual comparison [13]. The amount of filling can of course be changed.

The PLA is the most commonly used filament. It is easy to print from PLA material, has a low cost, is biodegradable and has good strength and durability. It has low thermal expansion, so it is also suitable for static structures. It has a low melting point, $175^{\circ} \mathrm{C}$. It is also possible to print detailed structures. It was proven to use a nozzle temperature of $210^{\circ} \mathrm{C}$ during printing. Due to uniform cooling and reduction of deformation problems, it is advisable to use a heated pad with a temperature of $50{ }^{\circ} \mathrm{C}$. Disadvantages include low resistance to external influences. It loses its thermal mechanical resistance even at $55^{\circ} \mathrm{C}$. Due to its low UV resistance, it is unsuitable for outdoor use. Wet grinding to prevent melting due to friction and subsequent deformation of the surfaces usually performs the surface treatment of the material after printing.

Table 1 Properties of PTFE balls during the experiment

\begin{tabular}{|l|l|l|l|}
\hline Quantity & Standard & Value & Unit \\
\hline Density & ISO 1183 & 2180 & $\mathrm{~kg} \cdot \mathrm{m}^{-3}$ \\
\hline Tensile strength & DIN EN ISO 527-1 & $22-25$ & $\mathrm{~N} \cdot \mathrm{mm}^{-2}$ \\
\hline Ductility & DIN EN ISO 527-1 & $>220$ & $\%$ \\
\hline Shore hardness & ASTM D 2240 & $55-59$ & $(\mathrm{D})$ \\
\hline Melting point & DIN 53736 & 327 & ${ }^{\circ} \mathrm{C}$ \\
\hline
\end{tabular}

The counterpart for the Ball on Flat friction test was a ball made of PTFE with $6.35 \mathrm{~mm}$ diameter. The material with the trade name Teflon is known for its sliding properties and has a wide application beyond the machine area. This material is stable in the temperature range from -170 to $260^{\circ} \mathrm{C}$. A PTFE balls are chemically stable 
and can be used in extreme conditions. They are often used in bearings and check valves, or as electrical insulators. Table 1 lists its selected properties.

Samples obtained by 3D printing technology were evaluated for surface microgeometry on a TalySurf CLI1000 device. The surface texture was measured with an inductive touch sensor [14]. The measurement took place on an area of $(2 \times 2) \mathrm{mm}$. A 3D model of the surface of the test specimen - see Figure 1.

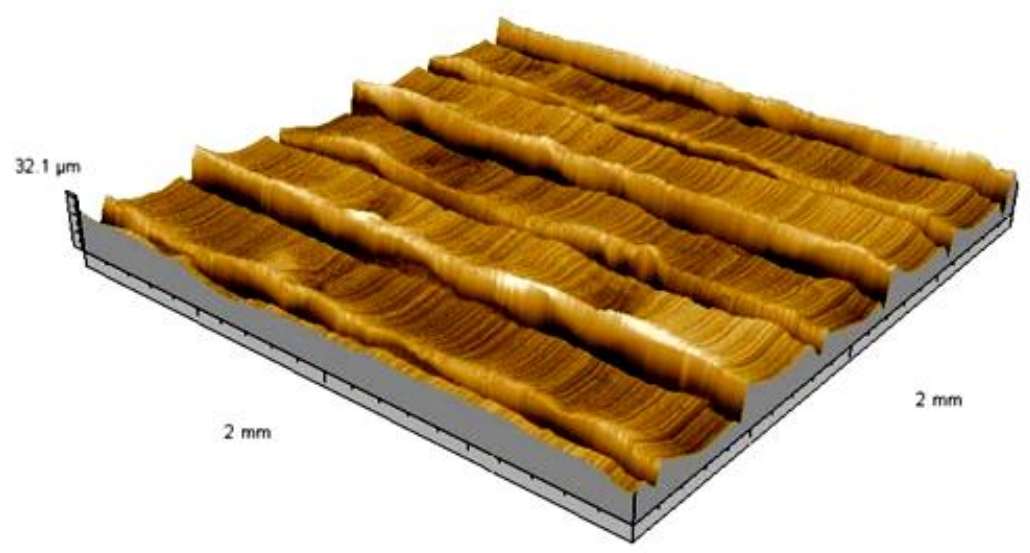

Figure $13 \mathrm{D}$ model of the sample surface made of PLA material

By measuring the surface of the inductive touch sensor it has been found that the path of the print material is periodically repeated with a step of about $0.4 \mathrm{~mm}$. The average surface roughness of the surface was $S a=3.81 \mu \mathrm{m}$. The maximum amplitude of the range of the measured area was $32.1 \mu \mathrm{m}$.

\section{EXPERIMENT}

The experiment was based on the Ball on Flat test on a UMT Bruker tribometer. The aim was to measure the coefficient of friction (COF). A defined load on a constant distance of $10 \mathrm{~mm}$ cyclically stressed the surface of the samples. The duration of the tests was constant 120 seconds. During the cyclic reciprocating motion, the tribological properties of the surface, primarily COF, and further visible surface changes were studied.

Secondarily it has been documented thermal stress of the specimen surface by thermal camera FLIR T610 see Figure 2. The thermal camera FLIR T640 records the temperature measurement of the sample surface [15]. Increased heat fundamentally affects the resulting wear, especially for PLA-type material, which is one of the 3D printable materials most susceptible to temperature-dependent softening. The values of applied loads (Normal forces) were $7 \mathrm{~N}, 20 \mathrm{~N}, 40 \mathrm{~N}, 60 \mathrm{~N}$ and $100 \mathrm{~N}$. The frequency was constant, $5 \mathrm{~Hz}$ in all tests. Traces obtained during tribological testing were documented and measured on an Olympus DSX 100 optical microscope.

A PTFE ball was used as a pin for the friction pair sample. The reason was the expected suitable sliding properties and the expected low coefficient of friction between the PLA material and the ball made of PTFE.

The aim of the experiment was to determine the real values of friction between the two materials. Friction, as a tribological process, can be characterized as the loss of mechanical energy during the relative movement of two surfaces that are in contact. During friction, a number of changes occur, in particular the mechanical energy changes into thermal energy, subsequently the tribological characteristics of the functional surfaces deteriorate. The result is the wear. The basic parameter of the contact pair property is the COF [16]. This COF, denoted $\mu$, is a dimensionless quantity and expresses the ratio between the friction force $F_{t}$ and the normal force $F_{N}$. The normal force is applied directly to the surface of the sample. 
$\mu=\frac{F_{t}}{F_{N}}$

According to the method of mutual movement of the functional surfaces, the coefficient of friction can be divided into the coefficient of sliding or shear friction and the coefficient of rolling friction. It is necessary to realize the fact that the friction force is negatively oriented towards the movement and its absolute value is less than the force necessary to set the body in motion.

The Ball on Flat method is utilized to measure the coefficient of friction $[17,18]$. The principle of measurement with the Ball on Flat method is to push the indenter, the ball into the test specimen by force. This force can be constant, increasing linearly [19], or it can vary according to the requirements of the experiment [20]. For the purposes of the experiment, a constant force was chosen. The test specimen moved in a straight line during the experiment. The test was performed dry, as we usually use in the case of steels [21,22].

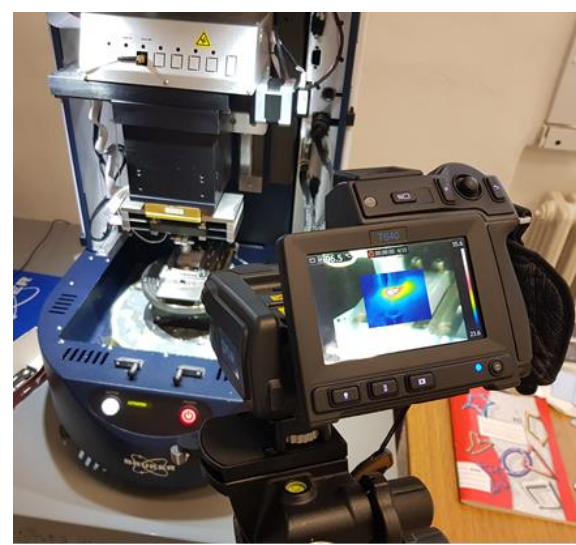

Figure 2a Experimental design, UMT Bruker tribometer and thermal camera FLIR T610 on a tripod

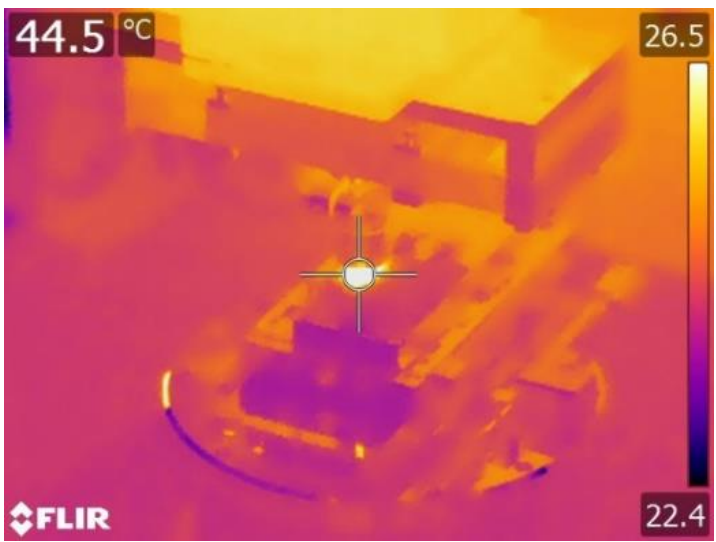

Figure $\mathbf{2 b}$ Example of measuring heat at the point of friction during the experiment, normal force $20 \mathrm{~N}$

\section{RESULTS AND DISCUSSION}

The data obtained during the experimental work were used to evaluate the COF and compare them. In addition to COF values, attention was also focused on the surface condition of the PLA material sample. On the other hand, attention was focused on the condition of the balls and surfaces, which were ground during the test. The surface condition of the samples and balls was documented on an Olympus DSX 100 optical microscope. The sample material showed small signs of damage. An example of wear, at a relatively high load of $60 \mathrm{~N}$ of normal force, is shown in Figure 3. Only at a load of $100 \mathrm{~N}$ (normal force) was the wear of the surface more significantly observable.

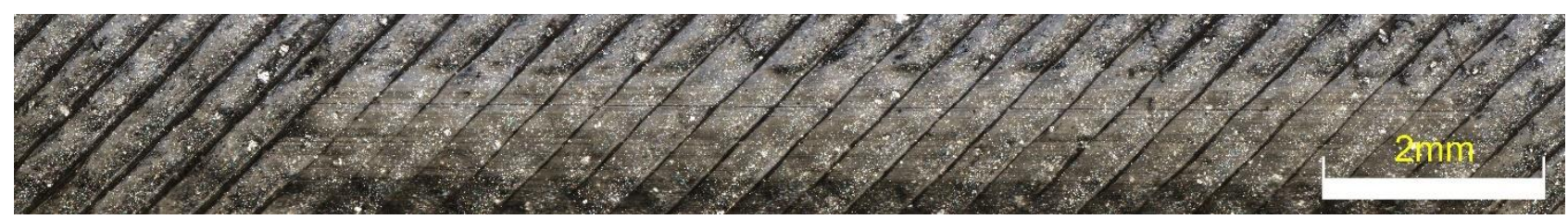

Figure 3 Example of a trace on a PLA sample, PTFE ball, normal force $60 \mathrm{~N}$

On the other hand, the canopy of the ball was ground at all applied loads during the experiments performed. The wear of the PTFE ball is documented in the matrix of figures, Figures $4 \mathbf{a}$ ) to e). The degree of wear of the individual balls is shown in Table 2. This value of wear increases in proportion to the increasing load of 
normal force applied to the indenter with the ball. The increase in wear is nearly linear with the value of reliability $R^{2}=0.9662$ as shown the graph in Figure 5 .

Table 2 The resulting parameters of tribological tests

\begin{tabular}{|l|c|c|c|c|c|}
\hline Normal force $(\mathrm{N})$ & $\mathbf{7}$ & $\mathbf{2 0}$ & $\mathbf{4 0}$ & $\mathbf{6 0}$ & $\mathbf{1 0 0}$ \\
\hline Wear diameter of the balls $(\mathrm{mm})$ & 1.14 & 1.57 & 2.07 & 2.39 & 2.95 \\
\hline Coefficient of friction (COF) $\mu$ & $0.0816 \pm$ & $0.0659 \pm$ & $0.0451 \pm$ & $0.0346 \pm$ & $0.0267 \pm$ \\
& 0.01212 & 0.00555 & 0.00649 & 0.00613 & 0.00545 \\
\hline
\end{tabular}

By measuring COF by the Ball on Flat method, the results with standard deviations shown in Table 2 were obtained. These are only the mean values from the measurement time of $120 \mathrm{~s}$. The change in COF and its alignment after approximately $20 \mathrm{~s}$ of test is evident from the graph in Figure 5. For a friction pair of a sample made of PLA and PTFE indenter in the shape of a ball with a diameter of $6.35 \mathrm{~mm}$, a decrease in COF value as a function of load (normal) force is evident. At a load of $7 \mathrm{~N}$ after approximately $100 \mathrm{~s}$ of test, an unexpected gradient change in COF occurred.

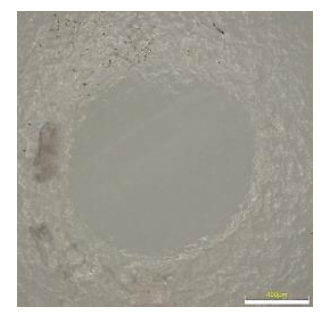

a) $F_{N}=7 \mathrm{~N}$

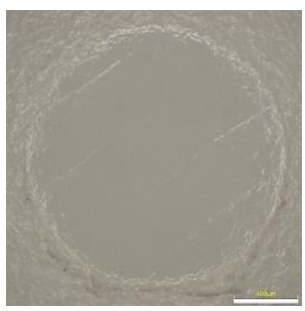

b) $F_{N}=20 \mathrm{~N}$

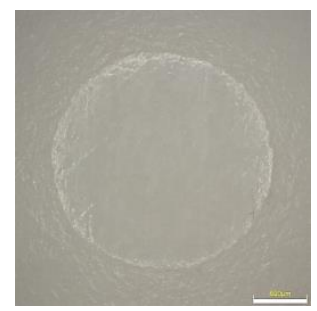

c) $F_{N}=40 \mathrm{~N}$

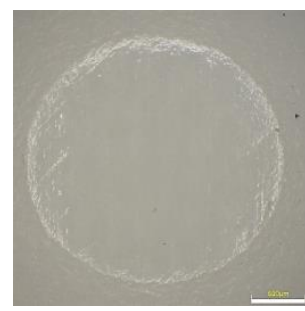

d) $F_{N}=60 \mathrm{~N}$

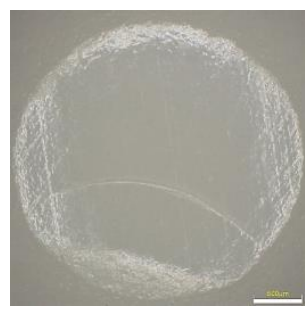

e) $F_{N}=100 \mathrm{~N}$

Figure 4 Wear of PTFE balls at specified normal forces

The temperature did not exceed $55^{\circ} \mathrm{C}$ during the test. Thus, the surface of the PLA sample did not melt. The decrease of COF values depending on the magnitude of the normal force has an exponential course with the reliability value $R^{2}=0.9453$ as the graph in Figure 5 shows.

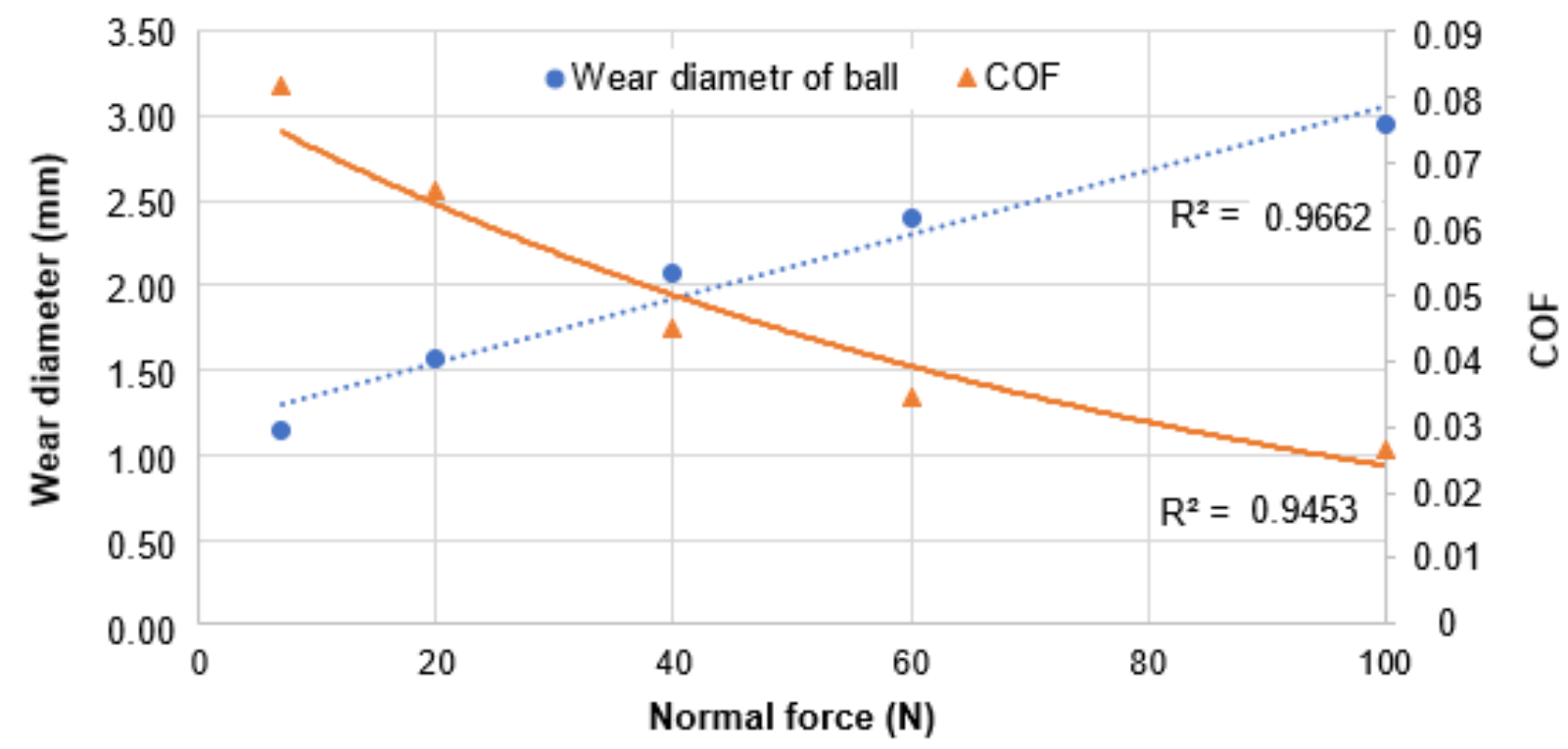

Figure 5 Comparison of dependencies Wear diameter of the balls and COF 


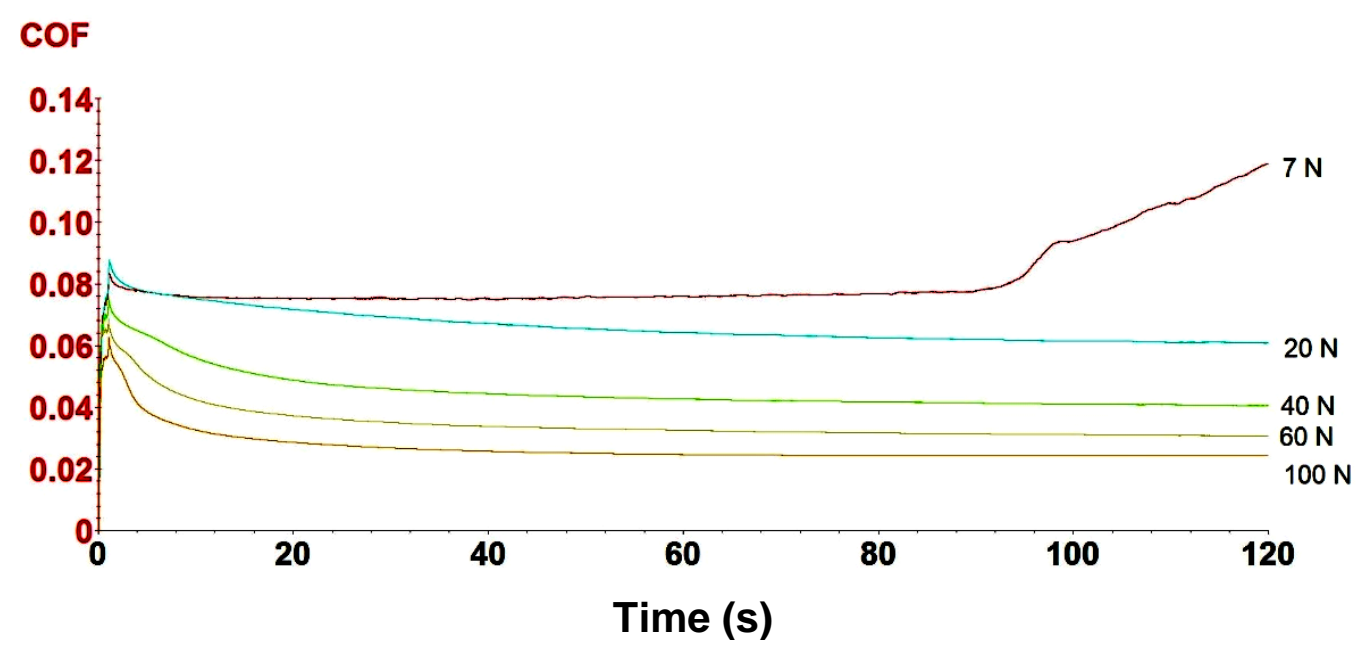

Figure 6 Comparison of COF dependences during the experiment

\section{CONCLUSION}

The article evaluated the PLA material, from which experimental samples were made for the tribological test. The test method was Ball on Flat. A $6.35 \mathrm{~mm}$ diameter PTFE ball was used in the indenter. During the test, tribological characteristics were measured and subsequently evaluated. The output was a graph of coefficients of friction versus time. A thermal camera monitored the place of contact of the two experimental subjects, i.e. the sample and the ball. The principle of the measurement was to check the maximum temperature reached. PLA material changes mechanical properties when the temperature reaches $55-60^{\circ} \mathrm{C}$.

The measurement of the coefficient of friction took place at levels of normal load $(7,20,40,60$ and 100) $N$. The test time was constant $120 \mathrm{~s}$. Reciprocal movement of the sample took place on a path of $10 \mathrm{~mm}$ with a frequency of $5 \mathrm{~Hz}$.

From a tribological point of view, the friction pair PLA and PTFE is also advantageous with regard to high loads reaching $100 \mathrm{~N}$. At this value of the normal load, the coefficient of friction reached the lowest values. There was no heating of the material, which would be at the limit or exceed the limit of the applicability of the PLA material in technical practice.

Another output of tribological tests was to determine the dependence of ball wear. The dependence of the wear area on the increasing load was almost linear with a reliability value of $R^{2}=0.9662$. On the other hand, the dependence of the values of the coefficient of friction on the magnitude of the normal force had an exponential course with the reliability value $R^{2}=0.9453$.

The obtained values of the coefficient of friction, the temperature generated during mutual contact or subsequently also measuring in particular the width of the tracks or the extracted material of the sample are further usable both for determining the wear coefficient on the one hand or comparing combinations of friction materials on the other hand. The reason is the effort to achieve low wear, while maintaining the required properties of the materials used in technical practice. The calculation of the wear coefficient from the wear values of the tracks after the Ball on Flat test can be a further continuation of the experimental investigation of the material used in 3D printing.

\section{ACKNOWLEDGEMENTS}

The paper has been prepared thanks to the support of the project "VAROPS (DZRO FVT 3)Military autonomous and robotic systems" and Surface technology in applications special techniques SV20- 


\section{REFERENCES}

[1] CHUA, C.K., LEONG, K.F. 3D Printing and Additive Manufacturing: Principles and Applications. 5th ed. World Scientific Publishing Company, 2017.

[2] AMBROSI, A., MOO, J.G.S., PUMERA, M. Helical 3D-printed metal electrodes ascustom-shaped 3D platform for electrochemical devices. Adv. Funct. Mater. 2016, vol. 26, pp. 698-703.

[3] NEIL, H., HAGUE, R., DICKENS, P. Rapid manufacturing: an industrial revolution for the digital age. John Wiley \& Sons, 2006.

[4] JOSHI, S.C., SHEIKH, A.A. 3D printing in aerospace and its long-term sustainability. Virtual and Physical Prototyping. 2015, vol. 10, no. 4, pp. 175-185.

[5] YONG, H., XUE, G., FU, J. Fabrication of low cost soft tissue prostheses with the desktop 3D printer. Scientific reports. 2014, vol. 4, p. 6973.

[6] BALLA, J., KRIST, Z., RACEK, F., MELŠA, P., NEUMANN, V., LE, C.I. Analysis and parameter identification of automatic Cannon carriages. Defence Science Journal. [online]. 2018, vol. 68 no. 6, pp. 525-532. ISSN 0011748X, Available from: https://doi.org/10.14429/dsj.68.12395

[7] TÚRÓ, T., NEUMANN, V., KROBOT, Z. Aspects of technical requirements for the future autonomy of military vehicles. In: Modelling and Simulation for Autonomous Systems. [online]. Rome, Italy: Springer International Publishing AG, part of Springer Nature, 2018, pp. 374-380. ISSN 0302-9743. ISBN 978-331976071-1. Available from: https://doi.org/10.1007/978-3-319-76072-8 26.

[8] KIM, M., KIM, S., AHN, N. Study of rifle maintenance and parts supply via 3D printing technology during wartime. In: 25th International Conference on Production Research Manufacturing Innovation: Cyber Physical Manufacturing. Chicago, USA: Procedia Manufacturing, 2019, vol. 39, pp. 1510-1516.

[9] YANG, W., HU, R., ZHENG, L., YAN, G., YAN, W. Fabrication and investigation of 3D-printed gun propellants. Materials and Design. 2020, vol. 192, p. 108761,

[10] LEE, J.Y., AN, J., CHUA, CH.K. Fundamentals and applications of 3D printing for novel materials. Applied Materials Today. 2017, vol. 7, pp. 120-133.

[11] TŘíSKA, V., CHLEBEČEK, T., HNIDKA, J., MAŇAS, K. Testing of the heating element integrated into the honeycomb sandwich structure for active thermography inspection. Journal of Sandwich Structures \& Materials. [online]. 2020. UNSP 1099636220927888. ISSN 1099-6362. Available from: https://doi.org/10.1177/1099636220927888.

[12] HUB, J. A study on topology optimization of airplane air brake bracing beam. In: International Conference on Military Technologies (ICMT). Brno: Institute of Electrical and Electronics Engineers Inc., 2019, p. 8870028. ISBN 978-172814593-8.

[13] JOSKA, Z., ANDRÉS, L., DRAŽAN, T., MAŇAS, K., POKORNÝ, Z., SEDLÁK, J. Influence of the shape of the filling on the mechanical properties of samples made by 3D printing. Manufacturing Technology. [online]. 2021, vol. 21, no. 2, pp. 199-205. ISSN: 12132489. Available from: https://doi.org/10.21062/mft.2021.024.

[14] DOBROCKÝ, D., STUDENÝ, Z., POKORNÝ, Z., JOSKA, Z., FALTEJSEK, P. Assessment of surface structure of machined surfaces. Manufacturing Technology. [online]. 2019, vol. 19, no. 4, pp. 563-572. ISSN: 12132489, Available from: https://doi.org/10.21062/ujep/335.2019/a/1213-2489/MT/19/4/563

[15] BARENYI, I., MAJERIK, J., POKORNY, Z., et al. Material and technological investigation of machined surfaces of the OCHN3MFA steel. Metallic Materials. [online]. 2019, vol. 57, no. 2, pp. 131-142, Available from: https://doi.org/10.4149/km 20191131.

[16] DOBROCKÝ, D., STUDENÝ, Z., POKORNÝ, Z., POSPICHAL, M., SMIDA, O. Effect of plasma nitriding on the notch toughness of spring steel. In: Metal 2016: 25th Anniversary International Conference on Metallurgy and Materials. Brno, Czech Republic: TANGER Ltd., 2016, pp. 1037-1044.

[17] STUDENÝ, Z., POKORNÝ, Z., DOBROCKÝ, D., JOSKA, Z., PROCHAZKA, J. Tribological properties of DLC coating for parts of weapons. In: ECS Transactions, 21st International Conference on Advanced Batteries, Accumulators and Fuel Cells. Brno, Czech Republic, 2020, vol. 99, no. 1, pp. 297-307.

[18] KRBAŤA, M., MAJERÍK, J., BARÉNYI, I., MIKUŠOVÁ, I., KUSMIČ, D. Mechanical and tribological features of the 90MnCrV8 steel after plasma nitriding. Manufacturing Technology. [online]. 2019, vol. 19, no. 2, pp. $238-242$. ISSN: 1213-2489, Available from: https://doi.org/10.21062/ujep/276.2019/a/1213-2489/mt/19/2/238. 
[19] HUTSAYLYUK, V., SNIEZEK, L., TORZEWSKI, J., CHAUSOV, M., BEREZIN, V., PYLYPENKO, A. Influence of preliminary combined loading on low cyclic fatigue deformation of aluminum alloy D16ChATV. In: ICSI 2015 The 1ST International Conference On Structural Integrity. [online]. Funcha, Moreira: PMGP; Tavares, PJ, 2015, vol. 114, pp. 18-25. Available from: https://doi.org/10.1016/j.proeng.2015.08.017.

[20] WACHOWSKI, M., KOSTUREK, R., SNIEZEK, L., MROZ, S., STEFANIK, A., SZOTA, P. The effect of post-weld hot-rolling on the properties of explosively welded Mg/Al/Ti multilayer Composite. Materials. [online]. 2020, vol. 13, no. 8, Article number 1930. Available from: https://doi.org/10.3390/ma13081930.

[21] PROCHAZKA, J., POKORNY, Z., DOBROCKY, D. Service behavior of nitride layers of steels for military Applications. Coatings. [online]. 2020, vol. 10, no. 10, p. 975. ISSN 2079-6412. Available from: https://doi.org/10.3390/coatings10100975.

[22] PROCHAZKA, J., POKORNY, Z., NGUYEN, H.Ch. Possibilities of the utilization of nitriding on case-hardening steels. In: Kazda T., Klein F., Sedlarikova M. ECS Transactions. [online]. Brno, Czech Republic: IOP Publishing Ltd, 2020, vol. 99, no. 1, pp. 255-263. ISSN 1938-5862. ISBN 978-160768539-5. Available from: https://doi.org/10.1149/09901.0255ecst. 